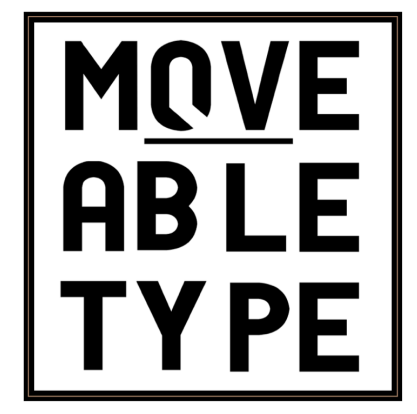

Coastal Works: Cultures of the Atlantic Edge, edited by Nicholas Allen, Nick Groom and Joss Smith and Love of Country: A Hebridean Journey by Madeleine Bunting [Joint review.]

Author[s]: Lottie Limb

Source: MoveableType, Vol.10, 'Peripheries' (2018)

DOI: $10.14324 / 111.1755-4527.089$

MoveableType is a Graduate, Peer-Reviewed Journal based in the Department of English at UCL.

(C) Lottie Limb 2018 COPYRIGHT. This is an Open Access article distributed under the terms of the Creative Commons Attribution License (CC-BY) 4.0https://creativecommons.org/licenses/by/4.0/, which permits unrestricted use, distribution, and reproduction in any medium, provided the original author and source are credited. 


\title{
THE ART OF LOOKING CLOSER
}

\section{LOTTIE LIMB}

\author{
Coastal Works: Cultures of the Atlantic Edge. \\ Eds Nicholas Allen, Nick Groom and Jos Smith. 2017. 292p. £,55. \\ Oxford University Press. ISBN 978-0-19-879515-5 \\ Love of Country: A Hebridean Journey. \\ Madeleine Bunting. 2016. 351p. f9.99. \\ Granta. ISBN 978-1-84708-518-4
}

In his celebrated study Archipelagic English (2008), John Kerrigan poignantly saw 'the future of the European Union providing one horizon' from which inter-island relationships could be re-imagined. ${ }^{1}$ A decade on, archipelagic criticism has much to offer. Coastal Works (2017), edited by Nicholas Allen, Nick Groom and Jos Smith, is an important contribution both to this field and the 'blue humanities' more generally. It comprises twelve scholarly essays each investigating 'the cultural imagination in relation to a distinctive geography' on the north Atlantic edge, eloquently unearthing trans-island tales. ${ }^{2}$ Madeleine Bunting's travel book Love of Country: A Hebridean Journey (2016) also uncovers island stories, acquiring a coastal perspective that I shall view through the clustered light of Coastal Works. The academic text is dedicated to Tim Robinson and his wife, Máiréad. As an archipelagic founder-figure, Robinson's fractal view of the Connemara coastline - variously informed by his skills as an artist, cartographer and writer - has shaped an exploration by him of what lies on the margin, a mapping out of the peripheries. As the editors identify in an elegant Introduction, that precedent involves posing the questions:

What level of detail has escaped the eye looking out from the centre? What sits precariously on the outer edge of perception or cultural memory? What new encounters become possible the closer we get to the edge of the known landscape? $?^{3}$

The collection of essays presents not so much a singular, coherent methodology or set of narrow answers as the flexuous consideration of those questions. Coastal Works, then, exemplifies the art of looking closer.

\footnotetext{
${ }^{1}$ John Kerrigan, Archipelagic English: Literature, History, and Politics 1603-1707 (Oxford: Oxford University Press, 2008), p. 2.

${ }^{2}$ Introduction, Coastal Works: Cultures of the Atlantic Edge, ed. by Nicholas Allen, Nick Groom and Jos Smith (Oxford: Oxford University Press, 2017), pp. 2-3.

${ }^{3}$ Ibid. p. 2.
} 
Its case studies are most insightful when using precise language to explore coastal particularities. 'Ecotone', a boundary zone where two ecosystems meet and overlap', proves an especially productive way of conceptualizing the shore as a permeable interface. ${ }^{4}$ Nick Groom's investigation into an anonymous 1722 satirical pamphlet, Thoughts of a Project for Draining the Irish Channel, is wonderfully elucidating, historicizing the application of "circulatory system" to the sea. In directly confronting the satire - hypothesizing what would have been the outcome of draining the Irish Sea in the 1720s - Groom's essay is characteristic of the experimental, open-minded and open-bordered approach the collection inspires.

Fiona Stafford's essay on John Ruskin's personal response to the Solway Firth is admirably self-reflexive, querying 'whether such an account can ever be representative of more general truths. ${ }^{5}$ Her brilliant close analysis of Ruskin's depiction of the estuary in his autobiography Praeterita (1889), so attentive to shifting light, is placed in conversation with other contemporary visions, and latterly Ciaran Carson's ventriloquised Ruskin in Belfast Confetti (1989). Moving from the etymology of 'estuary' ('an arm of the sea' or 'the tidal mouth of a great river') to Carson's call to 'let Belfast be the mouth of the poem' indicates the connective intricacy of this piece. ${ }^{6}$ Nicholas Allen's discussion of Carson's labyrinthine memoir The Star Factory (1997) is similarly inspired, suggesting that the Belfast poet's 'imaginative geometry' is particularly well suited to archipelagic criticism. ${ }^{7}$

As John Brannigan acknowledges at the start of his essay on Louis MacNeice, much has been written about the poet's search for 'home' and his 'place' within Irish and English literary criticism. ${ }^{8}$ The ascription of 'self-consciously archipelagic' is, then, a refinement of existing critical material, and a re-alignment of MacNeice's 'cultural precursors'. Gathering together MacNeice's coastal writing, and seeing his travelogue $I$ Crossed the Minch (1938) as 'shaped by a scaling of the Hebrides against the measure' of other places, is a useful re-calibration. ${ }^{9}$ Whilst this may not be the most original chapter in the book, it is testament to the critically sustainable nature of coastal work that it yields returns the closer we look, each time we return. Alongside literary accounts, Coastal Works also accounts for the visual arts, as in Margaret Cohen's penetrating analysis of Zarh Pritchard's

\footnotetext{
${ }^{4}$ Ibid. p. 5.

${ }^{5}$ Ibid. p. 43.

${ }^{6}$ Ibid. p. 45, p. 56. Quoting 'Farset', Ciaran Carson, Belfast Confetti (Newcastle upon Tyne: Bloodaxe Books, 1990), p. 49.

${ }^{7}$ Ibid. p. 64.

8 Ibid. p. 93.

${ }^{9}$ Ibid. p. 101.
} 
early twentieth-century submarine paintings. Generous colour re-productions accompany explanations of Pritchard's efforts to render an underwater world transmuted by the effect of water molecules on light. ${ }^{10}$ This meeting of optics and art follows two chapters on scientific coastal work. Ness Cronin's recuperation of the natural scientist Maude Delap offers a detailed study of her contribution to maritime ecologies, before examining Delap's Valentia island home in relation to the 'the spaces of domestic science' in late Victorian Britain and Ireland. Kyriaki Hadjiafxendi and John Plunkett chart the feedback between fieldwork on the coast of Devon and Victorian popular science, drawing attention to the gendering of seaside collecting as a female pastime.

The expansion of archipelagic criticism to include these natural histories owes much to Andrew McNeillie's literary journal Archipelago (2007-present), with its foregrounding of place. Its inter-island focus is the subject of Jos Smith's essay 'Fugitive Allegiances', which is a good place to orientate oneself in this collection. With its conversational and exciting range of approaches, Coastal Works reveals the Atlantic Edge as a plethora of peripheries with stories to tell with an abundance of imaginative resources. Of course these can help us to re-imagine our centre(s), and inevitably this study destabilizes that binary. But coasts are peripheries in a very real sense, and, as John R. Gillis argues in a dynamic Afterword, summarizing the ecological thrust of these essays: 'rather than seeing the shore as the edge of something else, it seems time to see it for itself, as one of those invaluable in-between places where two ecosystems meet and enrich one another'. ${ }^{11}$

Madeleine Bunting's book Love of Country: A Hebridean Journey takes the form of a voyage from Inner to Outer Hebrides, each chapter devoted to the cultural history of an island, under an enviable array of epigraphs (from Emily Dickinson to Rebecca Solnit). Bunting's theme is 'the making of myths, and how they flourish on the edge'. ${ }^{12}$ She looks at how the isles' peripheral location has informed their marginalized treatment, as during the Clearances on Rum, which have fed back into 'foundational myths' of Scottish identity. ${ }^{13}$ Though the book was six years in the writing, a political moment - the Scottish Referendum - again becomes a prism through which to reflect on the relationship between periphery and centre.

Coastal Works provides an evaluative lens through which we can see Love of Country at its sharpest when attending to particular coastal phenomena. Bunting's visit to Fingal's

\footnotetext{
${ }^{10}$ Ibid. p. 213.

${ }^{11}$ Ibid. p. 268.

12 Madeleine Bunting, Love of Country: A Hebridean Journey (London: Granta, 2016), p. 179.

${ }^{13}$ Ibid. p. 147.
} 
Cave on Staffa, for instance, moves from a volcanic explanation of the cave's unique column structure to that structure's ecstatic impression upon Sir Joseph Banks. The naturalist's naming of the cave is connected to a recently published cycle of epic poems on the Scottish legend of Fingal and Ossian, which influenced the Romantic movement in Britain and across the Atlantic. As in Stafford's essay, etymological excavation uncovers layers of human engagement - the cave was previously called Uamh Bhinn, the Melodious Cave - and older ways of perceiving the world.

Bunting's oscillations between anecdotal passages and Hebridean histories serve an affective function: they not only make the book more readable, eddying curiosity into learning, but simulate a quasi-narrative experience of looking. In Coastal Works, Gillis distinguishes between two ways of seeing: 'the landlubber's vision is pulled outward, but the mariner's focus is on what is hidden below the surface'. Bunting certainly has the selfawareness to characterize herself as a landlubber - the stories she tells are more interesting for that emotional complicity - and yet, over time, as mariners continue 'actually or mentally seeing shoals and eddies and sunken ships', she acquires a new sensory range. ${ }^{14}$ After Rum, the 'experience of touch and feel had crept into my mind. It passed after I had returned to the urgency of the city $[. .$.$] but the memory hung on, a way of thinking versed in the land. { }^{, 15}$

This feeling of disorientation is explored further in Coastal Works, and not simply in Pritchard's submarine paintings. Andrew McNeillie's chapter 'In the Labyrinth: Annotating Aran' recounts a journey begun in the company of Tim Robinson, before following the shadowy trails of an Aran sailor and RAF pilot. Appeals to local people prompt the speculation, with sentences depth-charged by the marine context: 'were they remembering or seeing? Or forgetting what they never saw into? ${ }^{36}$ Bunting's pursuit of artists drawn to the Hebrides makes similarly spiralling movements to McNeillie. Her study of George Orwell on Jura is particularly compelling, mingling careful research and conjecture to consider how Orwell 'found the clarity of vision' for Nineteen Eighty-Four (1949). ${ }^{17}$ This approach resonates with Daniel Brayton's more erudite analysis of Erskine Childers's The Riddle of the Sands (1903), which reads Childers's extraordinary spy thriller (and life) through the setting of the Frisian coast, decoding his conflicted national affiliations through the region's 'coastal indeterminacy'. ${ }^{18}$ Yet Bunting offers accumulative meditations on nationalism and the coastal imaginary, showing how 'the most intense imaginings of nation' have been

\footnotetext{
${ }^{14}$ Coastal Works, p. 265.

${ }^{15}$ Love of Country, p. 168.

${ }^{16}$ Coastal Works, p. 223.

${ }^{17}$ Love of Country, p. 55.

${ }_{18}$ Coastal Works, p. 119.
} 
projected onto the periphery. ${ }^{19}$ Such knowledge is pre-requisite for re-imagining relationships, and connecting with one another across the archipelago.

Coastal Works makes us more alert to Bunting's strategies in representing the Hebrides, but her companionship is enjoyable beyond its evaluative measure. Introspective passages are interspersed with unpretentious analogies describing 'folds of grey rock like the carcasses of exhausted elephants' and cliffs reminiscent 'of a bad 1980s haircut with frizzy curls on top'. ${ }^{20}$ Journalistic honesty is the stylistic correlative of Bunting's empathetic engagement with this seascape, making her final claim to the Hebridean Islands as a 'soul territory' ever more credible. ${ }^{21}$ Both these works get beyond 'postcard platitudes', delving into palimpsestic histories, pinpointing time and place to challenge 'a destructive mythology of the ocean's essentially ahistorical nature'. ${ }^{22}$ In their open-ended approach, they should inspire continued conversation - in the environmental, political, and many more fields besides.

Trinity College Dublin limbc@tcd.ie

${ }^{19}$ Love of Country, p. 119.

${ }^{20}$ Ibid. p. 209, p. 108.

${ }^{21}$ Ibid. p. 303.

22 Coastal Works, p. 111. 